\title{
Observation of Molecular Chains of Hydrolyzed Konjac Glucomannan by Scanning Probe Microscope
}

\author{
S. Komiya, R. Ojima, M. Takigami ${ }^{1)}$, R. Takahashi, and S. Takigami* \\ Gunma University, 1-5-1, Tenjin-cho, Kiryu, Gunma 376-8515 \\ 1) Gunma Industry Support Organization, Maebashi, Japan \\ *takigami@gunma-u.ac.jp
}

\begin{abstract}
Konjac glucomannan (KM) is a water soluble glucomannan with high molar mass. KM aqueous solution shows extremely high viscosity. KM can be depolymerized by chemical hydrolysis. The molar mass of hydrolyzed KM decreased with increase of hydrolysis time. The acid hydrolysis led chain scission of KM, but introduced no significant new chemical groups into the structure. The weight-averaged molar mass, $M_{\mathrm{w}}$, of original KM and that of $30 \mathrm{~min}$ hydrolyzed KM were 1.0 $\times 10^{6} \mathrm{Da}$ and $6.0 \times 10^{3} \mathrm{Da}$, respectively. The weight-averaged radius of gyration, $R_{\mathrm{G}}$, of original $\mathrm{KM}$ was $98.0 \mathrm{~nm}$. The $R_{\mathrm{G}}$ value decreased with increase of hydrolysis time and then reached to below $10 \mathrm{~nm}$ at $20 \mathrm{~min}$ of hydrolysis time. SPM image of original KM molecular chain showed string-like pattern. The contour length and the chain height of original KM were $1193 \mathrm{~nm}$ and 1.2 $\mathrm{nm}$, respectively. The chain height scarcely changed regardless of molar mass, but the contour length decreased significantly with increase of hydrolysis time. The chain lengths of KM with $M_{\mathrm{w}}$ of $5.9 \times 10^{5} \mathrm{Da}$ and $1.8 \times 10^{5} \mathrm{Da}$ were $688 \mathrm{~nm}$ and $268 \mathrm{~nm}$, respectively.

Key words: Konjac glucomannan, low molar mass, radius of gyration, chain length, light scattering, SPM
\end{abstract}

\section{INTRODUCTION}

Konjac glucomannan (KM) is a neutral glucomannan derived from tubers of Amorphophallas Konjac C. Koch, having a $\beta-1,4$ linked $\beta$-D-glucose $(G)$ and $\beta$-D-mannose $(\mathrm{M})$ backbone approximately in the ratio of 1:1.6. KM has side chains and the branching positions are considered to be the $\mathrm{C} 3$ of $\mathrm{G}$ and $\mathrm{M}$. An acetyl group is attached to ca.13 sugar residues [1]. Deacetylation occurs in the presence of alkali and a non-thermoreversible elastic gel is formed [2]. KM aqueous solution shows extremely high viscosity. Polysaccharides undergo depolymerization by various methods: $\gamma$-irradiation [3, 4], ultrasonic irradiation [3], chemical [5] and enzymatic hydrolyses [6].

From our previous study, KM can be depolymerized by hydrolysis method using citric acid at elevated pressure [7]. The molar mass of hydrolyzed KM decreased with increase of acid concentration and hydrolysis time. The Mark-Houwink-Sakurada equation for depolymerized KM by $\gamma$-irradiation was $[\eta]=5.30 \times 10^{-4} \mathrm{M}^{0.78}(\mathrm{dL} / \mathrm{g})$ $\left(4.9 \times 10^{4} \leq M_{\mathrm{w}} \leq 1.2 \times 10^{6}\right)[8,9]$. The $\alpha$ value of KM, 0.78 , indicates that $\mathrm{KM}$ molecule is a sort of flexible chain in aqueous solution.

Here, characteristic features of low molar mass KM prepared by acid hydrolysis were investigated using a Fourier transform infrared spectrophotometer, a ultraviolet-visible spectrophotometer and a size exclusion chromatograph equipped with a multiangle static light-scattering detector. The chain parameters of the hydrolyzed KM were measured by a scanning probe microscope. The effects of hydrolysis on radius of gyration and chain length are discussed.

\section{MATERIAL AND METHODS}

\subsection{Material}

Commercial konjac flour (Akagi Ohodama species) was supplied by Ogino Shoten Co. Ltd. The flour was purified by washing with aqueous ethanol solution several times before use.

\subsection{Preparation of low molar mass KM}

The purified $\mathrm{KM}$ and $5 \mathrm{mM}$ citric acid aqueous solution containing $0.001 \% \mathrm{NaN}_{3}$ were put in an autoclavable plastic bag to prepare $3 \% \mathrm{KM}$ aqueous solution. The KM solution was pressurized up to 0.247 $\mathrm{MPa}$ at $125^{\circ} \mathrm{C}$ using a pressure cooker. The hydrolyzed $\mathrm{KM}$ aqueous solution was centrifuged to remove cell wall debris before lyophilization.

2.3. Fourier transform infrared spectrum measurement Fourier transform infrared (FT-IR) spectra of the original and hydrolyzed KM were measured by a Magna 560 FT-IR spectrometer equipped with a Continu $\mu \mathrm{m}$ infrared microscope (Nicolet). The FT-IR spectrum of hydrolyzed KM was measured by transmission method.

\subsection{Ultraviolet-visible spectrum measurement}

Ultraviolet-visible (UV) spectra of the original and hydrolyzed KM were measured by a UV-3101 (Shimadzu).

\subsection{Molar mass measurement}

Molar mass of KM samples was determined by a multiangle static light-scattering (MALS) using a MALS detector from DAWN DSP (Wyatt Technology) with a vertically polarized $\mathrm{He}-\mathrm{Ne}$ laser operated at wavelength of $632.8 \mathrm{~nm}$. The photometer, which was calibrated using pure toluene, was connected to a size exclusion 
chromatography (SEC) column of GMPW XL $_{\text {(Tosoh) }}$ and a differential refractive index detector RI-71S (Shodex), which was used to determine KM concentration at each position of elution peak. The temperatures of the MALS flow cell and the column were controlled at $25^{\circ} \mathrm{C}$.

The KM sample solution was filtered through a cellulose acetate membrane filter with pore size of 0.45 $\mu \mathrm{m}$ (Sartorius). The recovery rates were generally above $99 \%$ for all of the samples we tested, indicating that hydrolyzed KM has good solubility to water.

Scattered light intensities at scattering angles between $15^{\circ}$ and $163^{\circ}$ were measured. $50 \mathrm{mM} \mathrm{NaNO}$ s solution was used as both solvent and eluent at $1 \mathrm{~mL} / \mathrm{min}$.

\subsection{Scanning probe microscope measurement}

The KM was dissolved in Barnsted water. KM solution $\left(1 \times 10^{-3} \mathrm{mg} / \mathrm{ml}\right)$ was deposited onto freshly cleaved mica. The sample was kept at room temperature until the surface was dried. KM molecular chain was observed using JSPM-5200 Scanning probe microscope (JEOL) with a silicon cantilever (NSC35/ALBS, $\mu$-masch) by alternating current (AC) mode.

\section{RESULTS AND DISCUSSION}

\subsection{FT-IR spectroscopy}

$\mathrm{KM}$ was hydrolyzed in $5 \mathrm{mM}$ citric acid solution for scheduled time. Fig. 1 shows typical FT-IR spectra of original $\mathrm{KM}$ and acid hydrolyzed KM. For original KM, absorption peaks assigned to $\mathrm{C}=\mathrm{O}$ stretching vibration of acetyl groups and $\mathrm{C}-\mathrm{O}-\mathrm{C}$ anti-symmetry stretching vibration of pyranose ring were observed at $1730 \mathrm{~cm}^{-1}$ and $1154 \mathrm{~cm}^{-1}$, respectively. Similar IR patterns were observed for the hydrolyzed KM. Since the absorbance ratio of $\mathrm{C}-\mathrm{O}-\mathrm{C}$ to $\mathrm{C}=\mathrm{O}$ was hardly changed even at 30 min hydrolysis, no elimination of acetyl groups occurred by the acid hydrolysis. Accordingly, it is inferred that the chemical structure of KM scarcely changed by acid hydrolysis.

\subsection{UV spectroscopy}

$\mathrm{KM}$ was hydrolyzed in $5 \mathrm{mM}$ citric acid solution for scheduled time. Fig. 2 shows typical UV spectra of original $\mathrm{KM}$ and acid hydrolyzed KM.

For original KM, absorption peak by carbonyl group was observed at $235 \mathrm{~nm}$ and absorption peak by polymer chain was observed below $250 \mathrm{~nm}$.

The hydrolyzed KM samples showed similar UV spectra with that of the original KM. These results corresponded with those of FT-IR.

3.2. Molar mass and radius of gyration of hydrolyzed Konjac glucomannan

SEC-MALS chromatograms of the hydrolyzed KM are shown in Fig.3. The chromatogram of original KM was a single peak and polydispersity index, defined by the ratio of $M_{\mathrm{w}}$ to $M_{\mathrm{n}}$, was 1.23 . The chromatogram shifted to lower molar mass with increasing hydrolysis time, but the width of peaks were in the range of 1.3 - 1.6. It is inferred that the decrease of molar mass is caused by the main chain scission of $\mathrm{KM}$ induced by the acid hydrolysis.

The weight average molar mass $\left(M_{\mathrm{w}}\right)$ and weight

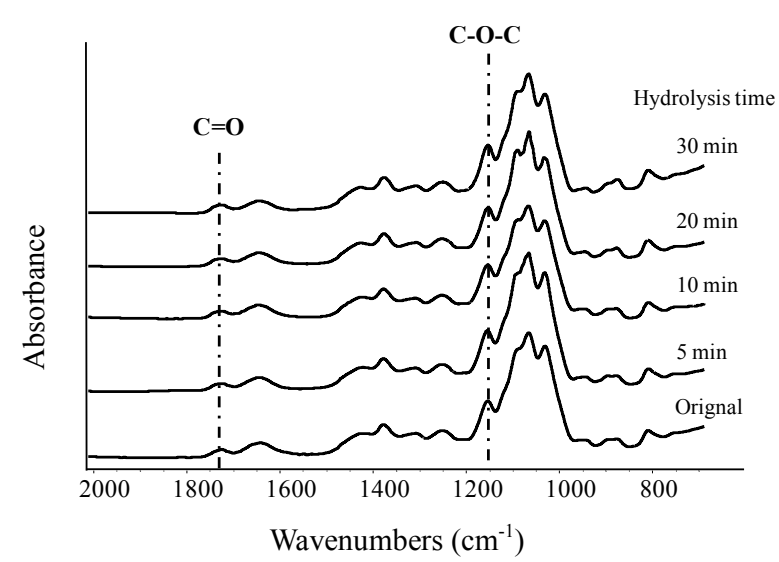

Fig.1 FT-IR spectra of hydrolyzed KM.

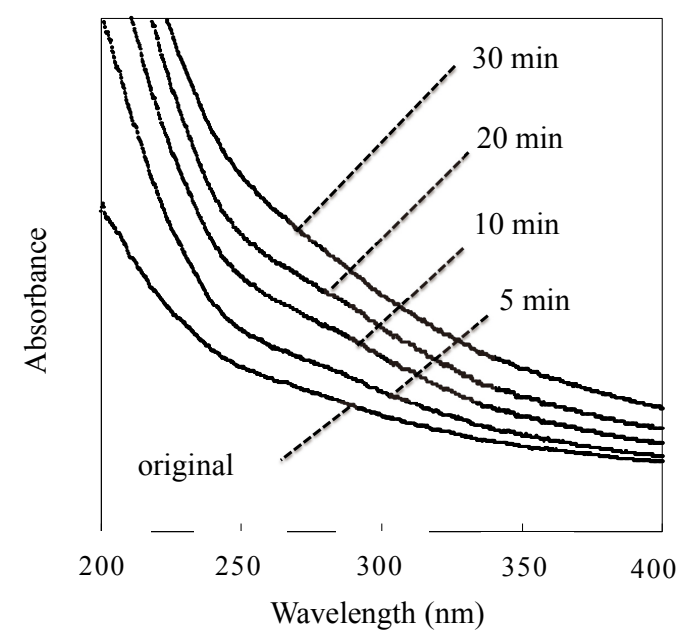

Fig.2 UV spectra of hydrolyzed KM.

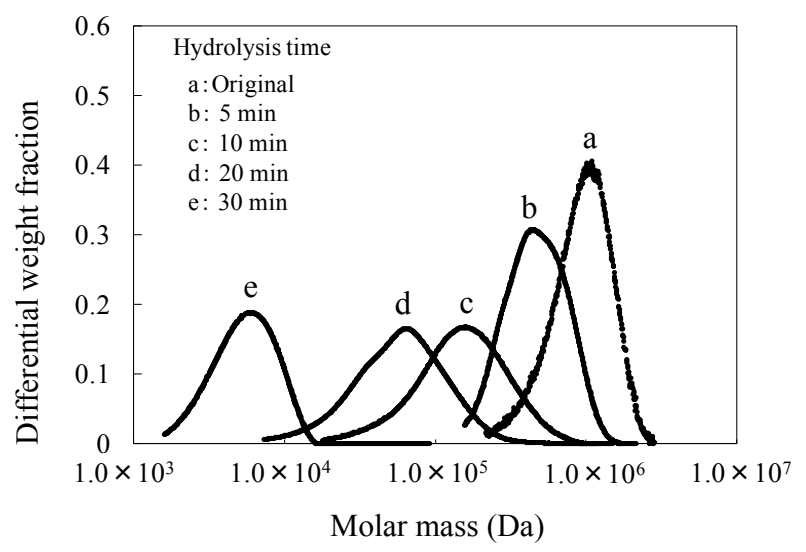

Fig.3 Molar mass distribution of hydrolyzed KM. 
average radius of gyration $\left(R_{\mathrm{G}}\right)$ were determined and plotted against the hydrolysis time in Fig.4. The $M_{\mathrm{w}}$ of original $\mathrm{KM}$ was $1.0 \times 10^{6} \mathrm{Da}$. The $\mathrm{M}_{\mathrm{w}}$ decreased with increase of hydrolysis time. The $\mathrm{M}_{\mathrm{w}}$ of $30 \mathrm{~min}$ hydrolyzed KM was $6.0 \times 10^{3} \mathrm{Da}$. The $R_{\mathrm{G}}$ of original $\mathrm{KM}$ was $98 \mathrm{~nm}$. The $R_{\mathrm{G}}$ value decreased with increase of hydrolysis time and then reached to $39.0 \mathrm{~nm}$ at 10 min of hydrolysis time. $R_{\mathrm{G}}$ values of the hydrolyzed KM more than $20 \mathrm{~min}$ were below $10 \mathrm{~nm}$.

\subsection{SPM image of Konjac glucomannan}

The SPM image of original KM is shown in Fig.5. The molecular chains showed string-like pattern. The height of the chain was ca.1.2 $\mathrm{nm}$. However, the width was ca. $80 \mathrm{~nm}$ (in general, width of polysaccharides chain was in the range of 0.1-1 nm [10]), and much more than the real width. The possible reason was broadened domino effect caused by interaction between the tiny needlepoint and different section of molecular chain in the course of scanning. Similar phenomenon was also reported for the observation of konjac glucomannan [10].

3.4. SPM image of low molar mass Konjac glucomannan

Fig. 6 and 7 show the SPM image of hydrolyzed KM with molar mass of $5.9 \times 10^{5}$ and $1.8 \times 10^{5} \mathrm{Da}$. The molecular chain of hydrolyzed KM with low molar mass also showed string-like pattern. Table 1 shows hydrolysis time, molar mass, radius of gyration, molecular height and length for hydrolyzed KM. The contour length decreased significantly with decrease of molar mass. The chain height $(1.2 \mathrm{~nm})$ scarcely changed regardless of molar mass. The chain length of $5.9 \times 10^{5}$ $\mathrm{Da}$ and $1.8 \times 10^{5} \mathrm{Da}$ hydrolyzed $\mathrm{KM}$ was 688 and 268 $\mathrm{nm}$. The result showed good correlation with the result of $M_{\mathrm{w}}$ and $R_{\mathrm{G}}$ determined by light scattering.

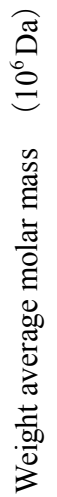

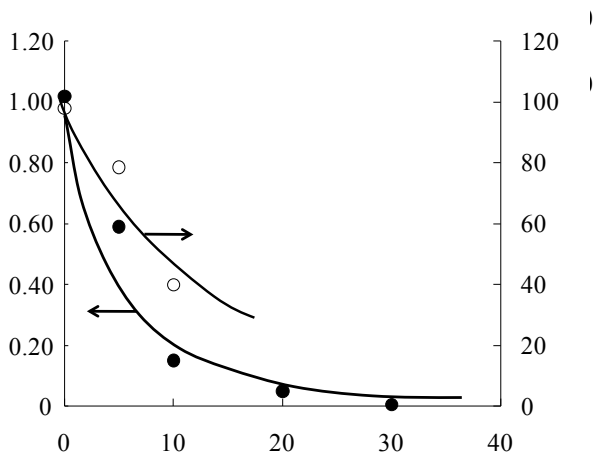

Hydrolysis time (min)

Fig.4 Effect of hydrolysis time on Molar mass and $\mathrm{R}_{\mathrm{G}}$ of hydrolyzed $\mathrm{KM}$.

The chain length of KM could be calculated by the following equation $[10,11]$,

$$
L=M_{\mathrm{W}} / M_{\mathrm{L}}
$$

,where $L$ is the contour length, $M_{\mathrm{W}}$ the weight average molar mass, and $M_{\mathrm{L}}$ the molar mass per unit contour length. The $M_{\mathrm{L}}$ value of KM is $983 \mathrm{Da} \mathrm{nm}^{-1}$.

The calculated contour length of low molar mass KM with $5.9 \times 10^{5} \mathrm{Da}$ and $1.8 \times 10^{5} \mathrm{Da}$ were $600 \mathrm{~nm}$ and 183 $\mathrm{nm}$, respectively. The result showed good agreement with the length observed by SPM measurement.

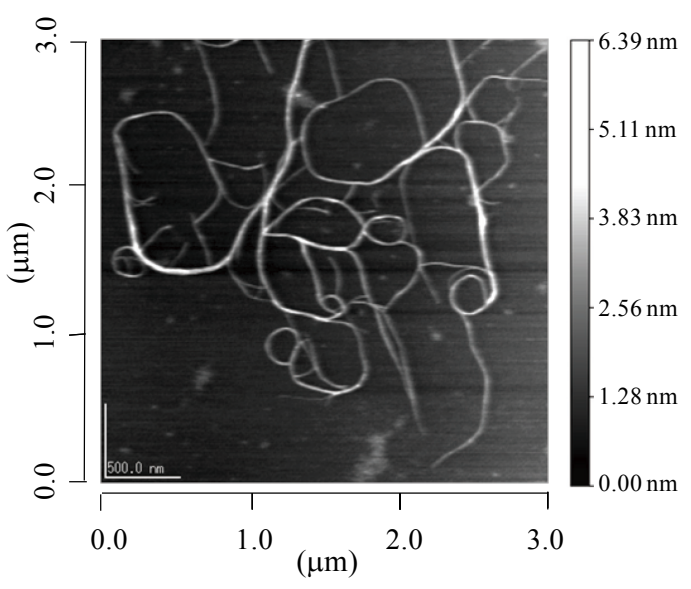

Fig.5 SPM image of deposited onto mica.

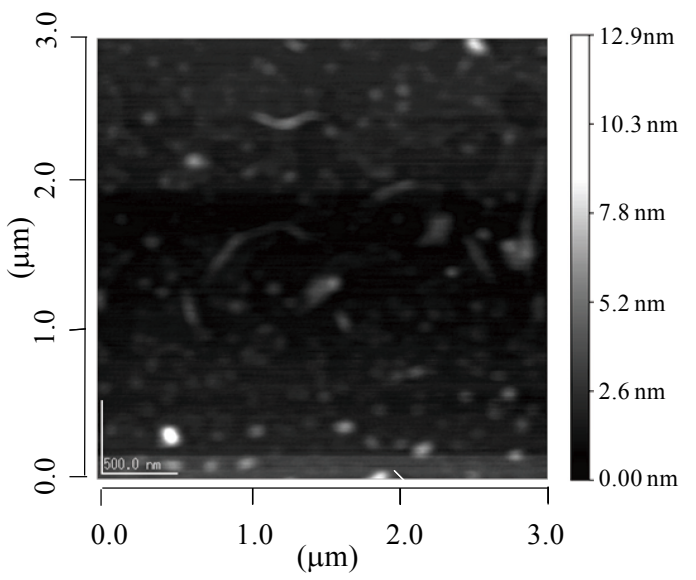


Table.1 Hydrolysis time, molar mass, radius of gyration, chain height and length for hydrolyzed KM.

\begin{tabular}{ccccc}
\hline Hydrolysis time & $\begin{array}{c}M_{\mathrm{w}} \\
(\mathrm{Da})\end{array}$ & $\begin{array}{c}R_{\mathrm{G}} \\
(\mathrm{nm})\end{array}$ & $\begin{array}{c}\text { Chain height } \\
(\mathrm{nm})\end{array}$ & $\begin{array}{c}\text { Contour length } \\
(\mathrm{nm})\end{array}$ \\
\hline Original & $1.0 \times 10^{6}$ & 98.0 & 1.2 & \\
$5 \mathrm{~min}$ & $5.9 \times 10^{5}$ & 78.6 & 1.1 & 688 \\
$10 \mathrm{~min}$ & $1.8 \times 10^{5}$ & 39.0 & 0.9 & 268 \\
\hline
\end{tabular}

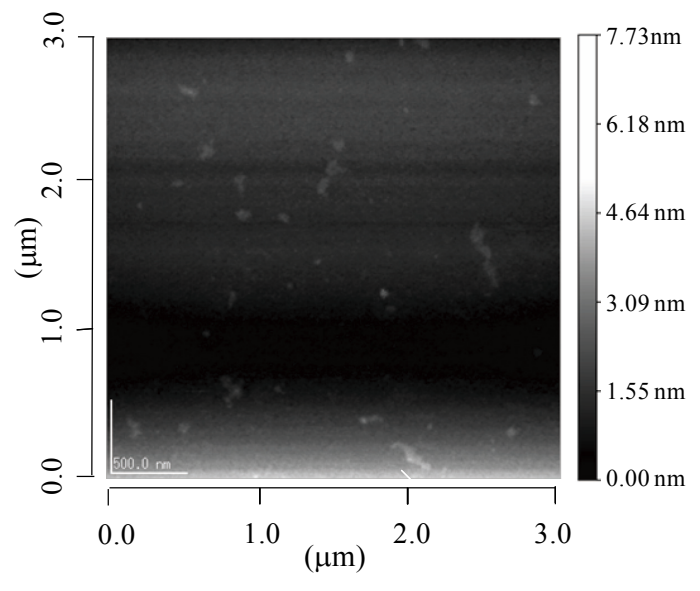

Fig.7 SPM image of hydrolyzed KM deposited onto

mica. $\mathrm{M}_{\mathrm{w}}$ was $1.8 \times 10^{5} \mathrm{Da}$

\section{CONCLUSIONS}

$\mathrm{KM}$ can be depolymerized by acid hydrolysis under elevated pressure. The molar mass of original KM was $1.0 \times 10^{6} \mathrm{Da}$. The molar mass decreased with increase of hydrolysis time. The molar mass of $30 \mathrm{~min}$ hydrolyzed $\mathrm{KM}$ was $1.8 \times 10^{5} \mathrm{Da}$. The $R_{\mathrm{G}}$ of original $\mathrm{KM}$ was 98.0 $\mathrm{nm}$. The $R_{\mathrm{G}}$ value decreased with increase of hydrolysis time and then reached to $39.0 \mathrm{~nm}$ at $10 \mathrm{~min}$ of hydrolysis time. Original KM molecular chain showed string-like pattern. The chain height and length-of original KM were $1.2 \mathrm{~nm}$. The chain height scarcely changed regardless of hydrolysis time. But, the chain length decreased significantly with decrease of molar mass. The chain lengths of $5.9 \times 10^{5} \mathrm{Da}$ and $1.8 \times 10^{5} \mathrm{Da}$ hydrolyzed KM were 688 and $268 \mathrm{~nm}$, respectively. The length observed by SPM measurement showed good agreement with the calculated length based on molar mass per unit length.

\section{REFERENCES}

[1] M. Maeda, H. Shimahara and N.Sugiyama, Agric. Biol. Chem., 44, 245-52 (1980).

[2] K. Maekaji, Agric. Biol. Chem., 38, 315-21 (1974).

[3] J. M. Wasikiewicz, F. Yoshii, N. Nagasawa, R. A. Wach and H. Mitomo, Phys. Chem., 73, 287-95 (2005).

[4] R. Yoksan, M. Akashi, M. Miyata and S. Chirachanchai, Rad. Res., 11, 471-80 (2004).

[5] K. Chang, B. Liang, M. C.Tai and F. H. Cheng, J. Agric. Food Chem., 49, 4845-51 (2001).

[6] M. Yoshimura, and K. Nishinari, Food Hydrocoll., 13, 227-233. (1999)

[7]R. Ojima, T. Makabe, P. Prawitwong, R. Takahashi, M. Takigami, and S. Takigami, Trans. Mat. Res. Soc. Jpn., 34, 477-480 (2009)

[8] P.Prawitwong, S.Takigami and G. O.Phillips, Food Hydrocoll., 21, 1362-1367 (2007).

[9] P.Prawitwong, S.Takigami R. Takahashi and G. O.Phillips, Trans. Mat. Res. Soc. Jpn., 31, 727-730 (2006).

[10] B. Li, B.J. Xie, Food. RES. INT., 39, 127-132 (2006)

[11] B. Li, B.J. Xie, J. F. Kennedy, Carbohydr. Polymers, 64, 510-515 (2006).

(Received May 1, 2010; Accepted November 18, 2010) 